\title{
Grouping of multicopper oxidases in Lentinula edodes by sequence similarities and expression patterns
}

Yuichi Sakamoto ${ }^{1 *}$, Keiko Nakade ${ }^{1,2}$, Kentaro Yoshida $^{1,3}$, Satoshi Natsume ${ }^{1}$, Kazuhiro Miyazaki ${ }^{4}$, Shiho Sato ${ }^{1}$, Arend F. van Peer ${ }^{1,5}$ and Naotake Konno $0^{1,6}$

\begin{abstract}
The edible white rot fungus Lentinula edodes possesses a variety of lignin degrading enzymes such as manganese peroxidases and laccases. Laccases belong to the multicopper oxidases, which have a wide range of catalytic activities including polyphenol degradation and synthesis, lignin degradation, and melanin formation. The exact number of laccases in L. edodes is unknown, as are their complete properties and biological functions. We analyzed the draft genome sequence of L. edodes D703PP-9 and identified 13 multicopper oxidase-encoding genes; 11 laccases in sensu stricto, of which three are new, and two ferroxidases. Icc8, a laccase previously reported in L. edodes, was not identified in D703PP-9 genome. Phylogenetic analysis showed that the 13 multicopper oxidases can be classified into laccase sensu stricto subfamily 1 , laccase sensu stricto subfamily 2 and ferroxidases. From sequence similarities and expression patterns, laccase sensu stricto subfamily 1 can be divided into two subgroups. Laccase sensu stricto subfamily 1 group A members are mainly secreted from mycelia, while laccase sensu stricto subfamily 1 group B members are expressed mainly in fruiting bodies during growth or after harvesting but are lowly expressed in mycelia. Laccase sensu stricto subfamily 2 members are mainly expressed in mycelia, and two ferroxidases are mainly expressed in the fruiting body during growth or after harvesting, and are expressed at very low levels in mycelium. Our data suggests that L. edodes laccases in same group share expression patterns and would have common biological functions.
\end{abstract}

Keywords: Fruiting body, Laccase, Lentinula edodes, Lignin degradation, Multicopper oxidase

\section{Introduction}

White-rot fungi produce a variety of extracellular lignin degrading enzymes, including lignin peroxidases, manganese peroxidases, and laccases. These enzymes have been receiving widespread attention because of their ability to degrade environmentally persistent xenobiotics as well as endocrine-disrupting chemicals like pentachlorophenol, polychlorinated biphenyls, and dioxins (Jeon et al. 2008; Fujihiro et al. 2009; Ullah et al. 2000).

Laccases (EC 1.10.3.2) belong to a group of polyphenol oxidases that contain copper atoms in their catalytic center and are therefore typically referred to as

\footnotetext{
*Correspondence: sakamoto@ibrc.or.jp

${ }^{1}$ Iwate Biotechnology Research Center, 22-174-4 Narita, Kitakami-shi,

Iwate 024-0003, Japan

Full list of author information is available at the end of the article
}

multicopper oxidases. They catalyze single-electron oxidation of phenolic substrates or aromatic amines, resulting in numerous products (Leonowicz et al. 2001). While plant laccases are mainly involved in formation of lignin polymers in a radical-based mechanism (Hoopes and Dean 2004; Ranocha et al. 2002; Sterjiades et al. 1992), fungal laccases have been reported to play roles in lignin degradation (Baldrian 2006; Thurston 1994), cell wall formation (Nakade et al. 2011), pathogenicity (Nosanchuk and Casadevall 2003) and fruiting body coloration (Nagai et al. 2003). The number of reports on the purification and characterization of laccases from white-rot fungi is becoming extensive (Baldrian 2006; Kumar et al. 2003); and includes reports on Trametes versicolor (Galhaup et al. 2002; Jönsson et al. 1997), Pleurotus ostreatus (Palmieri et al. 2000), and Lentinula edodes (Nagai et al. 2002, 2003). Sequence comparison

\section{Springer}


and transcription analysis has been carried out in several basidiomycetous fungi as well, such as Coprinopsis cinerea (Kilaru et al. 2006), P. ostreatus (Castanera et al. 2012; Pezzella et al. 2013), Flammulina velutipes (Wang et al. 2015) and Laccaria bicolor (Courty et al. 2009) and Schizophyllum commune (Madhavan et al. 2014). Recently, it was revealed that most basidiomyceteous fungi have more than 10 genes that encode different laccases in their genome (Floudas et al. 2012). Most laccases have been purified as secreted enzymes from fungal mycelia or as expressed recombinant enzymes, though some have been extracted from fruiting bodies (Lettera et al. 2010; Nagai et al. 2003). While these reports have generated detailed insights on sequence, structure, function and expression of specific laccases, an overall understanding of the relationship among biological spectrum, sequence similarity and expression pattern is still limited.

Lentinula edodes (Marasmiaceae), or shiitake as the mushroom is more popularly known, is one of the most important cultivated edible mushrooms as well as a white-rot fungus that degrades lignin in wood. Two laccases, Lcc1 (Nagai et al. 2002; Zhao and Kwan 1999) and Lcc4 (previously designated Lcc2; Nagai et al. 2003), have been purified from $L$. edodes and the corresponding genes have been cloned (Sakamoto et al. 2008, 2009). Nagai et al. (2009) purified another L. edodes laccase, Lcc6. Additional laccase encoding genes $(l c c 7-11)$ were reported in L. edodes strain L45A, and Lcc1, Lcc4, Lcc5, and Lcc7 were expressed in Pichia pastoris for characterization (Wong et al. 2013). More recently, genome sequence data in several species in the Marasmiaceae, to which $L$. edodes belongs, have become available in public databases for Omphalotus olearius, Dendrothele bispora, Moniliophthora perniciosa, and Gymnopus luxurians, allowing comparison of laccases among closely related species. In this report, we analyzed the draft genome sequence of $L$. edodes strain D703PP-9 and identified a total of 13 multicopper oxidases, including 3 novel laccase encoding genes $(l c c 12-14)$, and 2 genes (lcc10 and $l c c 11$ in Wong et al. 2013) that were later excluded from laccase sensu stricto subfamilies. Subsequent analysis of transcription patterns and phylogenetic relationships revealed that multicopper oxidases in $L$. edodes can be classified into 7 members of laccase sensu stricto subfamily 1 (and can be divided into two subgroups), 4 members of laccase sensu stricto subfamily 2 , and two ferroxidases (lcc10 and $l c c 11$ ). The relationship between their sequence similarities and biological functions is discussed.

\section{Materials and methods}

\section{Strains and culture conditions}

Lentinula edodes monokaryotic strain D703PP-9 (Miyazaki et al. 2008; ICMP No. 20921) was used for genome sequence analysis. L. edodes D703PP-9 and monokaryotic strain G408PP-4 (Miyazaki et al. 2008; NBRC No. 111202) were used for linkage mapping. A dikaryotic, commercially cultivated strain, L. edodes H600 (obtained from Hokken Co., Ltd, Tochigi, Japan: Sakamoto et al. 2008, 2009), was used for isolating RNA of multicopper oxidase-encoding genes. Mycelial cultures on sawdust media were prepared as described in Sakamoto et al. (2005). Growing fruiting bodies were prepared as described in Sakamoto et al. (2005), and for post-harvest analysis, harvested mature fruiting bodies were immediately transferred to a desiccator at $25{ }^{\circ} \mathrm{C}$ (Sakamoto et al. 2005) and sampled daily from day 0 (fresh) to day 4. Upon sampling, mushrooms were separated into pileus, gill and stipe, and immediately frozen in liquid nitrogen.

\section{RNA and CDNA preparation}

For RNA extraction, mycelia were cultured in MYPG liquid medium at $25{ }^{\circ} \mathrm{C}$ while shaking as described previously (Sakamoto et al. 2005). To extract RNA from mycelia grown on sawdust medium, a filter membrane (Isopore ${ }^{\mathrm{TM}}$ Membrane Filter; Millipore, MA, USA) was placed on the sawdust and covered with $1.5 \%$ agar. Mycelia from sawdust cultures were harvested 2 weeks after inoculation from the surface of the filter membrane. To extract RNA from fruiting bodies, primordia and fruiting bodies were prepared as described previously (Hirano et al. 1999; Nagai et al. 2003). cDNA was synthesized with a QuantiTect Reverse Transcription Kit (QIAGEN GmbH, Germany) following the manufacturer's instructions.

\section{Genome sequencing of $L$. edodes D703PP-9}

Genomic DNA was extracted from 2-week-old liquid cultures after crushing the mycelia in liquid nitrogen and using a MasterPure Yeast DNA Extraction Kit (Epicentre Biotechnologies, WI, USA) following the manufacturer's instructions. Libraries for genome sequencing were prepared using a TruSeq DNA Sample Prep Kit v2 (Illumina, CA, USA) and 76 bp paired-end sequencing was performed with an Illumina Genome Analyzer IIx system. De novo sequences were assembled using Velvet assembler version 0.7.34 (2) (http://www.ebi.ac.uk/ zerbino/ velvet/) by varying several parameters. We chose a set of contigs created under the conditions generating the longest N50 for further analyses. The blastx algorithm (ftp://ncbi.nlm.nih.gov/blast/executables/blast+/LATEST/) was used for identification of laccases. To predict 
transcripts for laccase encoding genes, the WISE2 algorithm was used (http://www.ebi.ac.uk/Tools/psa/ genewise/).

\section{Cloning and sequencing of multicopper oxidase-encoding genes}

Sequence data of $l c c 1$ through $l c c 6$ has been deposited in DDBJ (accession numbers Lcc1: AB822542; Lcc2: AB822543; Lcc3: AB822544; Lcc4: AB822545; Lcc5: AB822546; Lcc6: AB822547), and $l c c 1$ and $l c c 4$ have been previously reported (Sakamoto et al. 2008, 2009). For cloning of $l c c 7$ through $l c c 14$ (Lcc7: AB822548; Lcc9: AB822552; Lcc12: AB822549; Lcc13: AB822550; Lcc14: AB822551), we amplified the genes from cDNA synthesized from $L$. edodes H600 RNA extracted from mycelia or fruiting bodies. Open reading frames of $l c c 7, l c c 9$, and $l c c 12$ through $l c c 14$ were amplified using primer sets listed in Additional file 1: Table S1 and Ex Taq polymerase (TaKaRa, Bio. Inc., Kyoto, Japan), then sequenced using an AB3130XI sequencer (Applied Biosystems, CA, USA). Signal peptides of each laccase were predicted using SignalP (http://www.cbs.dtu.dk/services/SignalP/) algorithm.

\section{Phylogenetic analysis}

Multicopper oxidase-encoding genes were analyzed phylogenetically by alignment of the respective amino acid sequences (data set Additional file 1: Table S2) using ClustalW software (http://www.ddbj.nig.ac.jp/ search/clustalw-j.html). The phylogram was constructed using the neighbor-joining method, and trees were drawn using FigTree (http://tree.bio.ed.ac.uk/software/figtree/). Bootstrapping was carried out with 1000 replications.

\section{Protein detection and purification}

Anti-sera for Lcc1 and Lcc4 were respectively described in Sakamoto et al. (2008) and Yano et al. (2009). The peptides used in the immunization (custom service of TakaRa Bio. Inc., Kyoto, Japan) were designed using the Epitope Adviser 2.1 program (FQS, Fukuoka, Japan) to identify putative Lcc2 epitopes (NVQQGKRYRFRMISIACDA, TGGLNSGILRYQGAPDADP and RSADNTTYNYKNPVRRD), Lcc3 epitopes (GAPEEEPQTSQPLSSN, TSDSSEYNFKNPVRRD, EDTRDTKKDDMIPAD), and Lcc5 epitopes (CSEPGTPEVTSVLALNE, CQLVPLENPGAPGEPE, and EDVADWNTTQTPSTAWDDC). Western blot analysis was carried out following the procedure described in Sakamoto et al. (2008). Purification steps for Lcc2, Lcc4, Lcc5 and Lcc13 are summarized in Additional file 1: Table S3, and amino acid sequences were determined using an ABI Procise 491HT Protein Sequencing System (Applied Biosystems, CA, USA).
Laccase activity was measured following the methods described in Nagai et al. (2002).

Linkage mapping of multicopper oxidase-encoding genes For single-strand conformation polymorphism analysis, biotin-labeled PCR products were diluted 50- to 100-fold in $1 \times$ TBE buffer $(89 \mathrm{mM}$ Tris- $\mathrm{HCl}, \mathrm{pH} 8.0,89 \mathrm{mM}$ boric acid, 2 mM EDTA), $6 \%$ (w/v) sucrose, and $0.33 \%$ tartrazine. DNA in the diluted solution was denatured at $96{ }^{\circ} \mathrm{C}$ for $5 \mathrm{~min}$, cooled on ice and loaded on a $15 \times 40 \mathrm{~cm}$ vertical $5 \%$ HydroLink Long Ranger polyacrylamide gel (AT Biochem Malvern, PA, USA) in $1 \times$ TBE buffer, then electrophoresed at $14{ }^{\circ} \mathrm{C}$ for $90 \mathrm{~min}$ at $30 \mathrm{~W}$. DNA was transferred to MSI nylon membranes (MSI, MA, USA) and visualized using a Phototope-Star Detection Kit (New England Biolabs, MA, USA).

Allele-specific PCR was performed in $20 \mathrm{mM}$ Tris$\mathrm{HCl}$ (pH 8.5), $50 \mathrm{mM} \mathrm{KCl}, 2.5 \mathrm{mM} \mathrm{MgCl} 2,0.16 \mathrm{mM}$ each dNTP, $0.08 \mu \mathrm{M}$ each primer, $5 \mathrm{ng}$ genomic DNA, and 0.25 units Platinum Taq DNA polymerase (Invitrogen, CA, USA) in a total volume of $12.5 \mu \mathrm{L}$ overlaid with mineral oil. The thermal cycling program (performed on a PE480 instrument, PerkinElmer (PerkinElmer, MA, USA) consisted of denaturation for $1 \mathrm{~min}$ at $95^{\circ} \mathrm{C}, 35$ cycles of $95^{\circ} \mathrm{C}$ for $30 \mathrm{~s}, 55^{\circ} \mathrm{C}$ for $90^{\circ} \mathrm{s}, 72^{\circ} \mathrm{C}$ for $30 \mathrm{~s}$, and a $10 \mathrm{~min}$ final incubation at $72{ }^{\circ} \mathrm{C}$ with subsequent cooling to $4{ }^{\circ} \mathrm{C}$. The sequences of the primers used are shown in Additional file 1: Table S4.

Only the data for segregation in a 2:2 ratio in each tetrad was used for linkage analysis. The linkage of the markers was tested based on the LOD score (the threshold of the LOD score was 3.0, and the maximum distance was $25 \mathrm{cM}$ ). The MapMaker version 3.0 computer program was used for linkage analysis. In this program, an efficient algorithm that allowed a simultaneous multipoint analysis of any number of loci (Lander et al. 1987) was used. The loci were grouped using the "GROUP" (two-point analysis) and "COMPARE" commands. The Kosambi mapping function (Kosambi 1943) was applied to determine the distance between two loci.

\section{Analysis of expression of multicopper oxidase-encoding genes by real-time PCR}

The expression of $l c c 1$ in mycelia, young fruiting bodies during development, and fruiting bodies after harvest was analyzed by real-time PCR. Total RNA was isolated using the MasterPure Yeast RNA Extraction Kit (Epicentre Biotechnologies, WI, USA) and reverse transcribed using a QuantiTect kit (QIAGEN GmbH, Germany) according to the manufacturer's instructions. Real-time PCR was performed using SYBR Premix Ex Taq reaction solution (TaKaRa, Bio. Inc., Kyoto, Japan) and a StepOne Plus real-time PCR system (Applied Biosystems, 
CA, USA). To analyze the level of transcription of $l c c 1$ through 14 (except for $l c c 8$ : Wong et al. 2013), we used the primer sets listed in Additional file 1: Table S5. We also analyzed the expression of gpd (Hirano et al. 1999) as an internal control using the primers gpd-rtU and gpd-rtL (Sakamoto et al. 2008). To standardize the results, mRNA levels of multicopper oxidase-encoding genes were determined based on the ratio between the transcript levels of these multicopper oxidase-encoding genes and $g p d$. The expression patterns were analyzed by $\Delta \Delta C T$ method (Livak and Schmittgen 2001) with three replicates, and the expression level of mycelia cultivated in liquid medium was used as a calibrator.

\section{Results}

\section{Prediction of multicopper oxidases from the draft sequence of $L$. edodes}

In order to identify multicopper oxidases including laccases in L. edodes D703PP-9 (Miyazaki et al. 2008), we obtained a draft genome sequence based on de novo assembly of short read sequences from an Illumina genome analyzer (GAIIx). The total length of the resulting contigs was approximately $35.5 \mathrm{Mbp}$ (Table 1 ), which is roughly similar to the genome size of the basidiomycetous mushroom fungi $C$. cinerea $(37.5 \mathrm{Mbp}$, Stajich et al. 2010), S. commune (38.5 Mbp, Ohm et al. 2010), and Agaricus bisporus (30.0 Mbp, Morin et al. 2012), yet smaller than that of L. bicolor (60.7 Mbp, Martin et al. 2008). The quality of the draft genome (assembled contigs) was assessed through blastx searches against known $L$. edodes genes available in protein databases (336 proteins). Of these proteins, $99.5 \%(321 / 336)$ were represented in the draft genome, indicating sufficient quality for gene identification in $L$. edodes. Next, we predicted multicopper oxidase-encoding genes based on sequence similarities, and full-length multicopper oxidase-encoding genes were curated using the GeneWise algorithm. From the predicted multicopper oxidase-encoding genes of D703PP-9, we found $l c c 1$ through 11 except for $l c c 8$ (Additional file 1: Table S6, Wong et al. 2013), and 3 new laccase encoding genes $(l c c 12$ through $l c c 14)$. These genes (lcc1 through 14, except for $l c c 8$ ) were deposited in DDBJ (accession numbers Lcc1: AB822542; Lcc2: AB822543; Lcc3: AB822544; Lcc4: AB822545; Lcc5:AB822546; Lcc6:AB822547; Lcc7:AB822548; Lcc9: AB822552; Lcc10: LC018712; Lcc11: LC018713; Lcc12: AB822549; Lcc13: AB822550; Lcc14: AB822551). To validate the gene models for the newly identified laccases (lcc12 through lcc14), we cloned the respective encoding genes (accession numbers: Lcc7: AB821483; Lcc9: AB821487; Lcc12: AB821484; Lcc13: AB821485; Lcc14: AB821486) newly from L. edodes strain $\mathrm{H} 600$ and sequenced the cDNA of each gene to confirm its open reading frame, the number
Table 1 Summary of draft genome sequence of $L$. edodes strain D703P-9

\begin{tabular}{lr}
\hline Analysis & \multicolumn{1}{c}{ Results } \\
\hline No of contigs & 35,534 \\
Sum of bps (bp) & $35,696,002$ \\
Max length (bp) & 219,501 \\
Min length (bp) & 69 \\
n50 (bp) & 23,581 \\
Putative ORF & 8271 \\
\hline
\end{tabular}

of introns and the promoter region (Additional file 1: Table S7). Sequence similarities among the putative amino acid sequences of the cDNAs of these multicopper oxidase-encoding genes are summarized in Table 2, which shows that several multicopper oxidases shared higher sequence similarity and can be clustered. Lcc1 and Lcc6 had the highest similarity (81.4 \%), and Lcc5 had higher similarity to Lcc1 $(67.1 \%)$ and $l c c 6$ (65.6\%) compared with other multicopper oxidases. Lcc2, Lcc3, Lcc4 and Lcc7 shared higher similarity with each other (62-69 \%). Lcc9, Lcc13 and Lcc14 also shared the highest similarity with each other $(84.5-87 \%)$. On the other hand, Lcc10, Lcc11 and Lcc12 had lower sequence similarity to all other multicopper oxidases in L. edodes (25$30 \%$ in Lcc10 and Lcc11, and 27-47 \% in Lcc12; Table 2). Phylogenetic analysis (Fig. 1) revealed that multicopper oxidases in $L$. edodes could be categorized into laccase sensu stricto subfamily 1 (Lcc1, Lcc5, Lcc6, Lcc2, Lcc3, Lcc4 and Lcc7), laccase sensu stricto subfamily 2 (Lcc9, Lcc12 Lcc13 and Lcc14) and ferroxidases (Lcc10 and Lcc11) following the previous classification of multicopper oxidases (Kües and Rühl 2011; Hoegger et al. 2006).

\section{Structure of multicopper oxidase-encoding genes in $L$. edodes}

Analysis of alignments of multicopper oxidases-encoding genes suggested that all laccase encoding genes (laccase sensu stricto subfamily 1 and subfamily 2 ) had the 4 signature sequences (Fig. 2) defined by Kumar et al. (2003) and Kilaru et al. (2006). Two ferroxidases (Lcc10 and Lcc11) had low similarity to laccases sensu stricto (Table 2), but also had the 4 signature sequences (Fig. 2). Lower similarity was observed in multicopper oxidases in laccase sensu stricto subfamily 2, except for Lcc12, in signature 1 (L1). In Lcc9, Lcc13 and Lcc14 in laccase sensu stricto subfamily 2 , the conserved histidines and the intermediate tryptophan (His-Trp-His) in the N-terminal copper binding element L1 were missing (indicated as triangles), and the conserved His in $\mathrm{L} 2$ has been changed to Gln, and the His in L3 to Asn in Lcc9, 13, and 


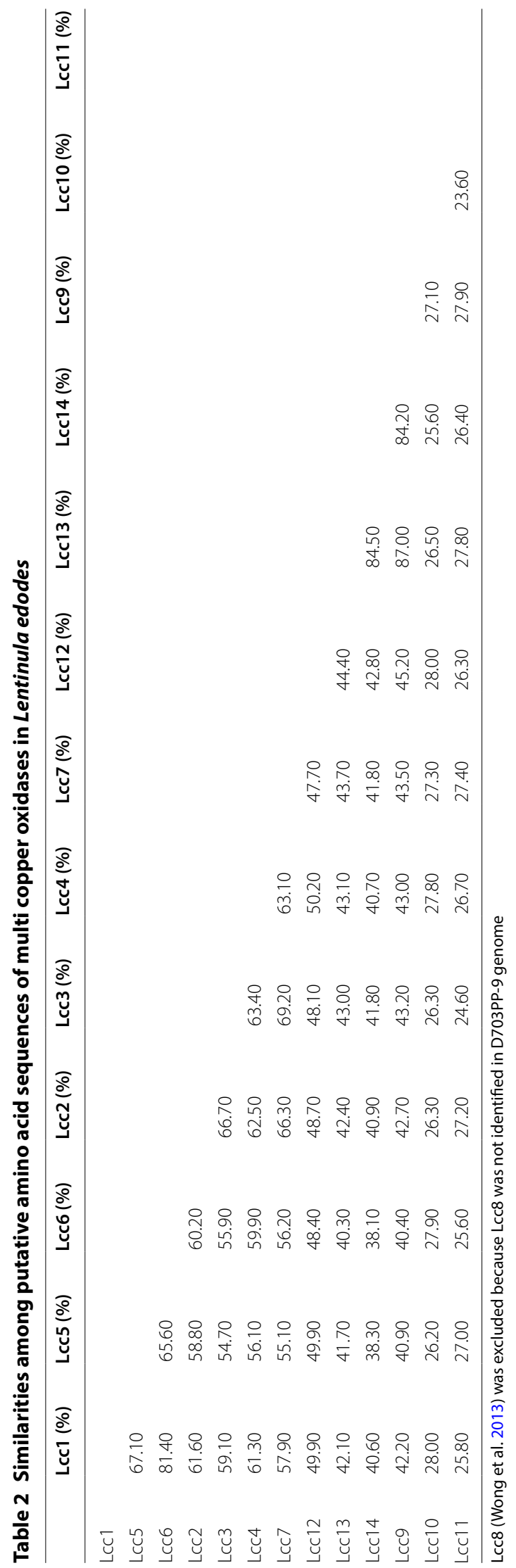




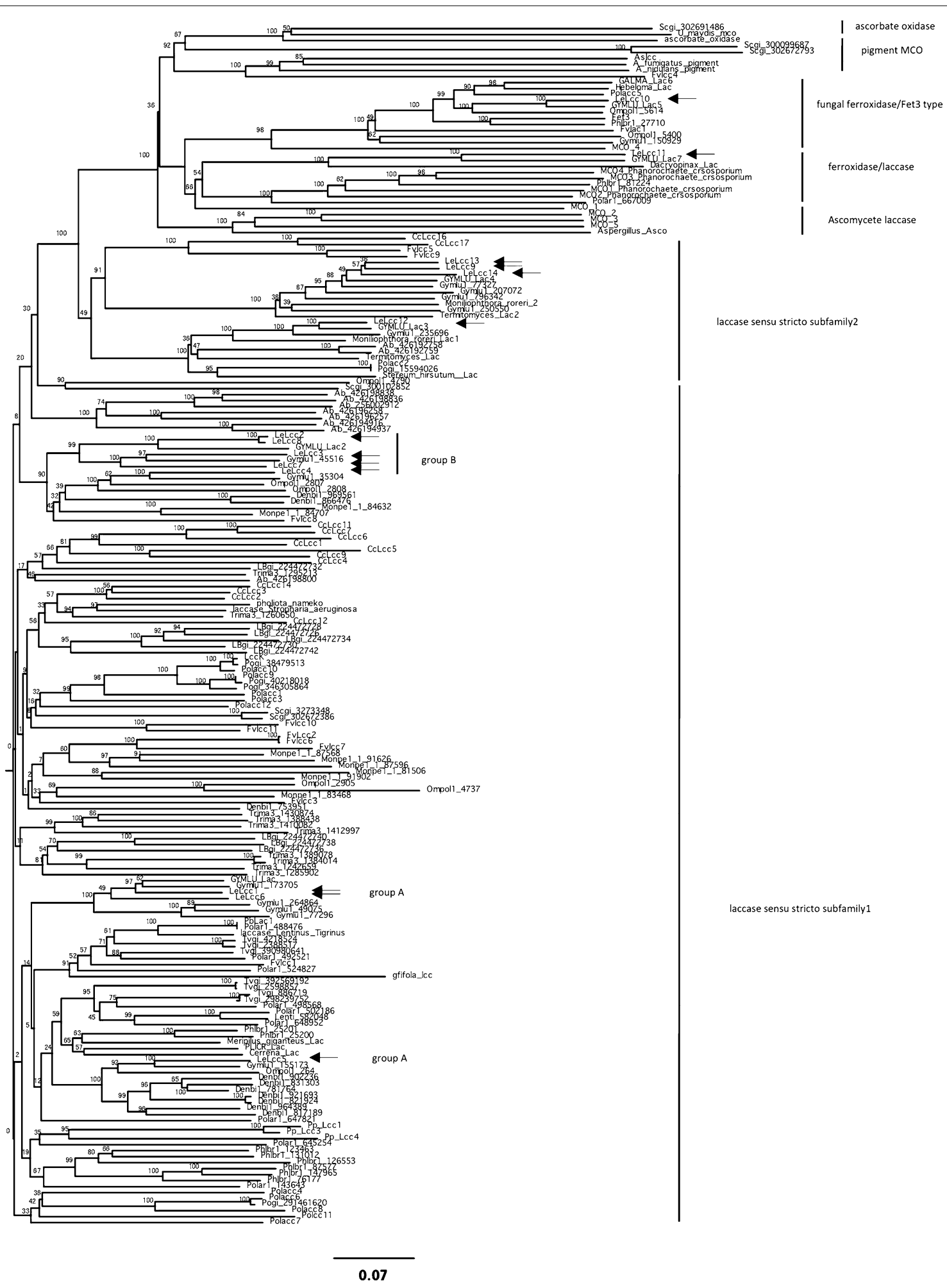

Fig. 1 Phylogenetic analysis of laccases in L. edodes. Accession numbers of each multicopper oxidase gene are summarized in Additional file 1: Table S2. The phylogram was constructed using the neighbor-joining method. The scale bar indicates a distance of 0.07, and the numbers on branches indicate percentage bootstrap support values (based on 1000 replications). Multicopper oxidases in L. edodes are indicated with arrows 


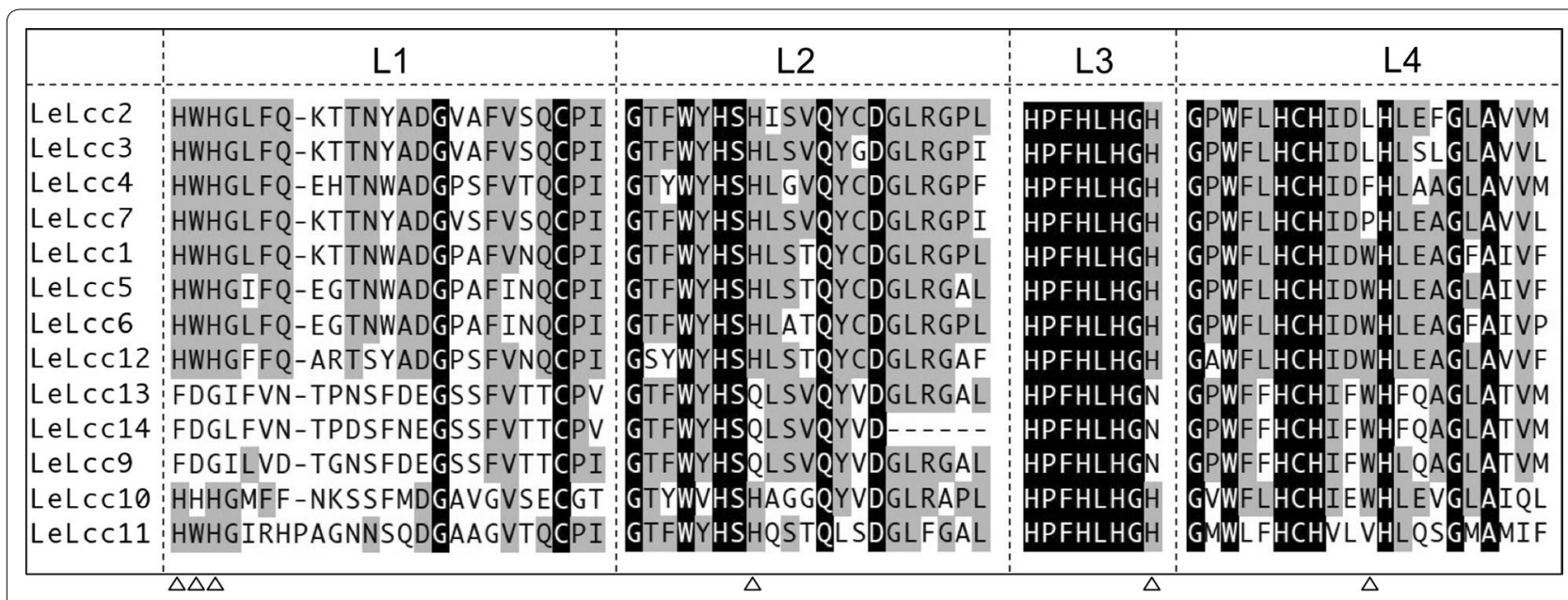

Fig. 2 Signature sequences of laccases in L. edodes. Black boxes indicate perfectly conserved amino acids, and gray boxes indicate partially conserved amino acids. Triangles indicate characteristic differences among groups of multicopper oxidases in $L$. edodes

14 (Fig. 2, indicated as triangles). Copper ion sites in laccases are classified into two types: type I (T1), where the electrons from the reducing substrates are accepted, and a type I/type III pair (T2/T3), which is assembled in a T2/T3 trinuclear cluster where electrons are transferred to perform the reduction of $\mathrm{O}_{2}$ to $\mathrm{H}_{2} \mathrm{O}$ (Ferraroni et al. 2007; Piontek et al. 2002). Lcc9, Lcc13 and Lcc14 each have the conserved histidines for T1 copper binding, but lack several T2/T3 copper binding histidines, suggesting different affinity to T2/T3 copper ions than laccase sensu stricto subfamily 1 . We found a difference in amino acid sequence in two groups (group A: Lcc1, Lcc5 and Lcc6: group B: Lcc2, Lcc3, Lcc4 and Lcc7) in laccase sensu stricto subfamily 1 , a tryptophan neighboring the copper binding conserved histidine in L4 (Fig. 2, indicated as a triangle). This presumably is involved in different substrate specificities of laccases in group A and group B in laccase sensu stricto subfamily 1 .

Signal peptide analysis of multicopper oxidases showed that except for Lcc11 in L. edodes, these proteins have a putative signal peptide $(\mathrm{D}$-cutoff $=0.450)$, and Lcc1, Lcc2, Lcc3, Lcc4, Lcc5, Lcc6 and Lcc10 have higher D-values than the other laccases (Additional file 1: Figure S1). Lcc1, Lcc2, Lcc3, Lcc4, Lcc5 and Lcc6 have been purified and their N-terminal amino acid sequences analyzed (Lcc1: Nagai et al. 2002; Lcc6: Nagai et al. 2009; Lcc2, Lcc4, Lcc5 and Lcc13: this study, Additional file 1: Table S3; Figure S2). The N-termini of Lcc1, Lcc5, Lcc6, and Lcc13 were identical to the putative $\mathrm{N}$-terminal sequences indicated by SignalP; therefore, the Lcc1, Lcc5, Lcc6, and Lcc13 signal peptides will likely be recognized and mediate secretion. The N-termini of Lcc 2 and Lcc4 could not be analyzed, as they were blocked (Additional file 1: Table S3), suggesting that N-termini of these laccases would not be digested as signal peptides.

To analyze the distribution of laccase genes in the $L$. edodes genome, localization was carried out using a previously constructed linkage map of $L$. edodes (Miyazaki et al. 2008). The 13 multicopper oxidase-encoding genes were spread over 7 linkage groups. Comparably, in $P$. ostreatus, 12 laccases are located in 5 linkage groups (Castanera et al. 2012). No L. edodes laccases were located close together except for $l c c 9$ and $l c c 14$ (Fig. 3), in contrast to $C$. cinerea, in which four sets of laccases are located in tandem (Kilaru et al. 2006), or P. ostreatus, in which 7 laccase encoding genes are located on chromosome VI (Castanera et al. 2012).

\section{Transcription patterns of $L$. edodes multicopper oxidases}

Except for $l c c 1$ (Nagai et al. 2002; Sakamoto et al. 2008) and lcc4 (Nagai et al. 2003; Sakamoto et al. 2009; Yano et al. 2009), the expression patterns of multicopper oxidase-encoding genes in $L$. edodes have not been well characterized. Using real-time PCR (Fig. 4) and calculation of expression as the ratio relative to expression in mycelia grown in liquid culture, we compared expression patterns of individual multicopper oxidases in L. edodes.

In laccase sensu stricto subfamily $1, l c c 1$ was more highly transcibed in mycelia than in fruiting bodies (Fig. 4), in agreement with previous reports (Sakamoto et al. 2008), The corresponding protein Lcc1 was secreted into liquid culture (Nagai et al. 2002) and sawdust media (Additional file 1: Figure S3). lcc6 was transcribed in mycelia grown on sawdust media (Fig. 4, Additional file 1: Figure S3 and as shown in Nagai et al. 2009), and also transcribed in fruiting bodies (Fig. 4). lcc5 was expressed in fruiting bodies after harvest, but was transcribed at 


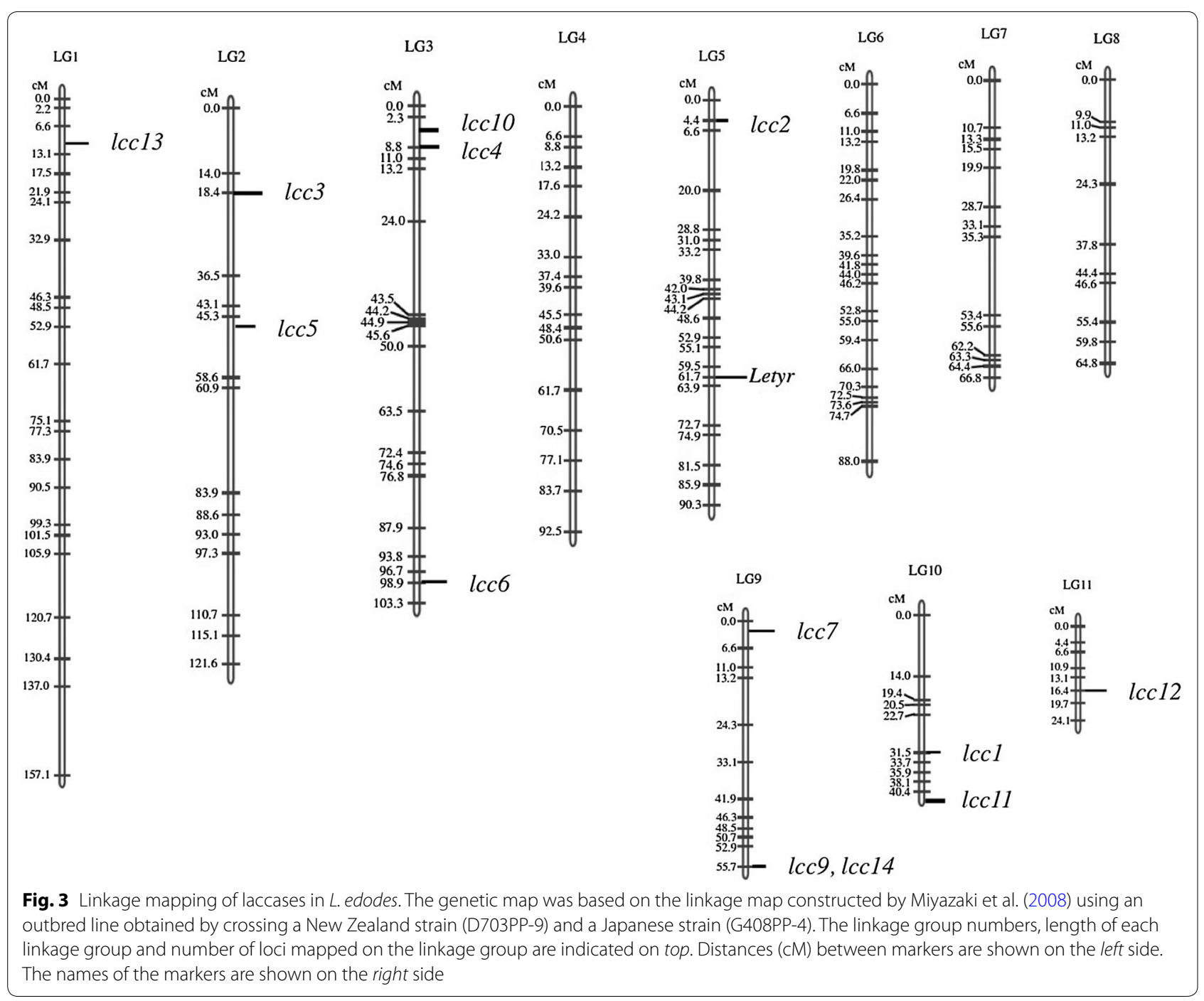

low levels in liquid culture medium and in mycelia cultured on sawdust media as a colony. However, Lcc5 was found to be secreted in the outer edges of the colonies (Additional file 1: Figure S3; Nagai et al. 2009).

Transcription of $l c c 2, l c c 3, l c c 4$ and $l c c 7$ (laccase sensu stricto subfamily 1) was low in mycelia grown in liquid medium or on sawdust medium (Fig. 4). Genes $l c c 2$ and $l c c 3$ were transcribed in the fruiting body, transcription increased during growth of the fruiting body, and transcription was higher in the pileus than in the stipe. Transcription of $l c c 2$ also increased in the gills immediately after harvesting of the fruiting body (Fig. 4, Additional file 1: Figure S5). However, transcription of $l c c 3$ in gills was very low during post-harvest preservation. Western blotting confirmed the presence of Lcc2 and Lcc3 in fruiting bodies, especially in the pileus (Additional file 1: Figure S4). Gene $l c c 4$ was specifically transcribed in gills after harvesting of the fruiting body (Fig. 4, Additional file 1: Figure S5) at days 3 and 4 after harvest, and was transcribed more slowly than $l c c 2$ (in case of $l c c 2$, transcribed from day2 after harvest). Gene $l \mathrm{cc} 7$ was expressed specifically in fruiting bodies, but transcription was lower after harvest than in fresh fruiting bodies. These observations suggest that members of laccase sensu stricto subfamily 1 group B are mainly transcribed in fruiting bodies.

The laccases in sensu stricto subfamily $2, l c c 9, l c c 12$, $l c c 13$, and $l c c 14$, showed varying transcription in mycelia and fruiting bodies. Genes $l c c 12, l c c 13$ and $l c c 14$ were transcribed in mycelia grown on sawdust medium while $l c c 9$ was not or was transcribed at low levels. Transcription of lcc14 was also elevated in fruiting bodies after harvest. Gene $l c c 9$ was mainly expressed in fruiting bodies after harvest. 


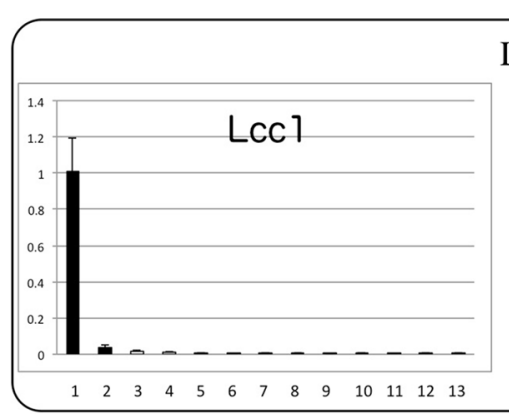

Laccase sensu stricto family 1 groupA
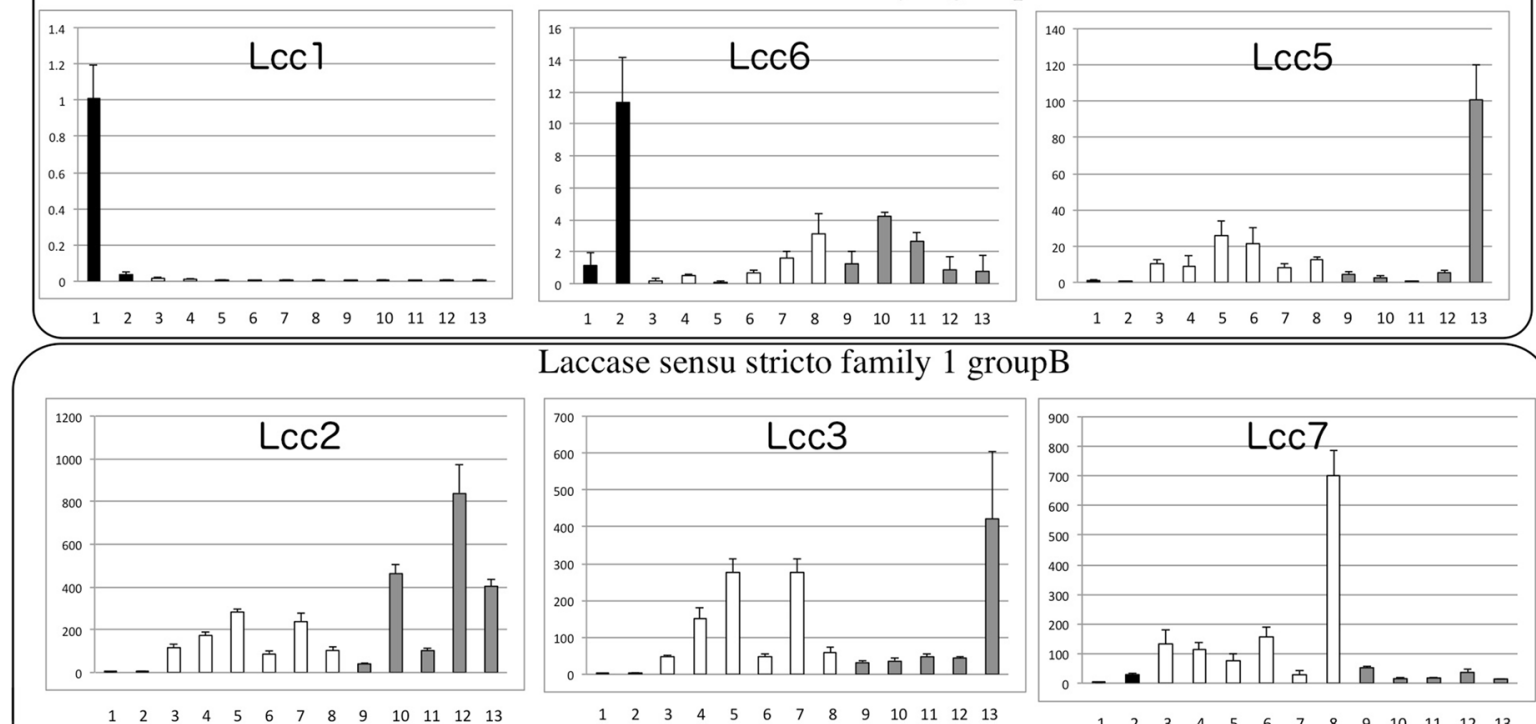

Laccase sensu stricto family 1 groupB
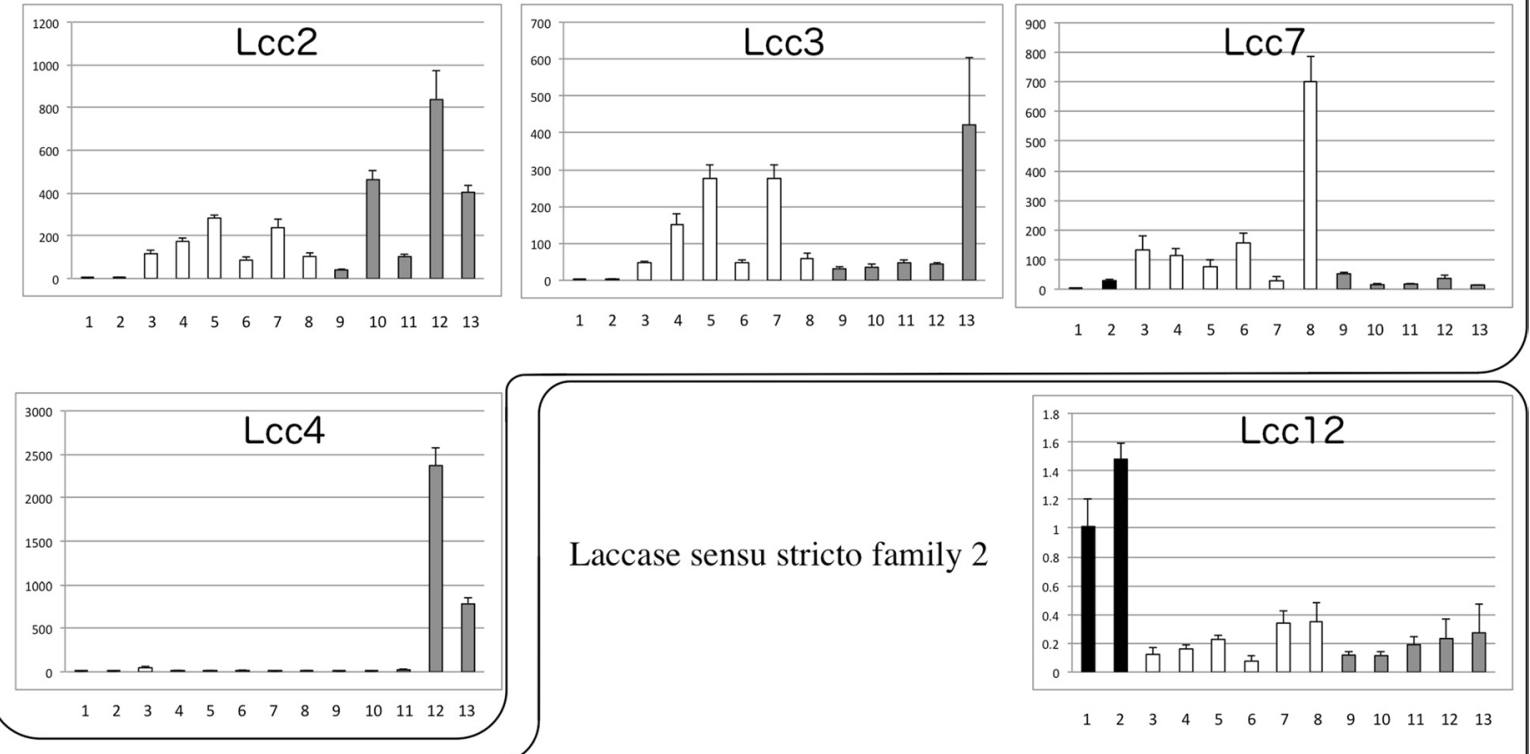

Laccase sensu stricto family 2
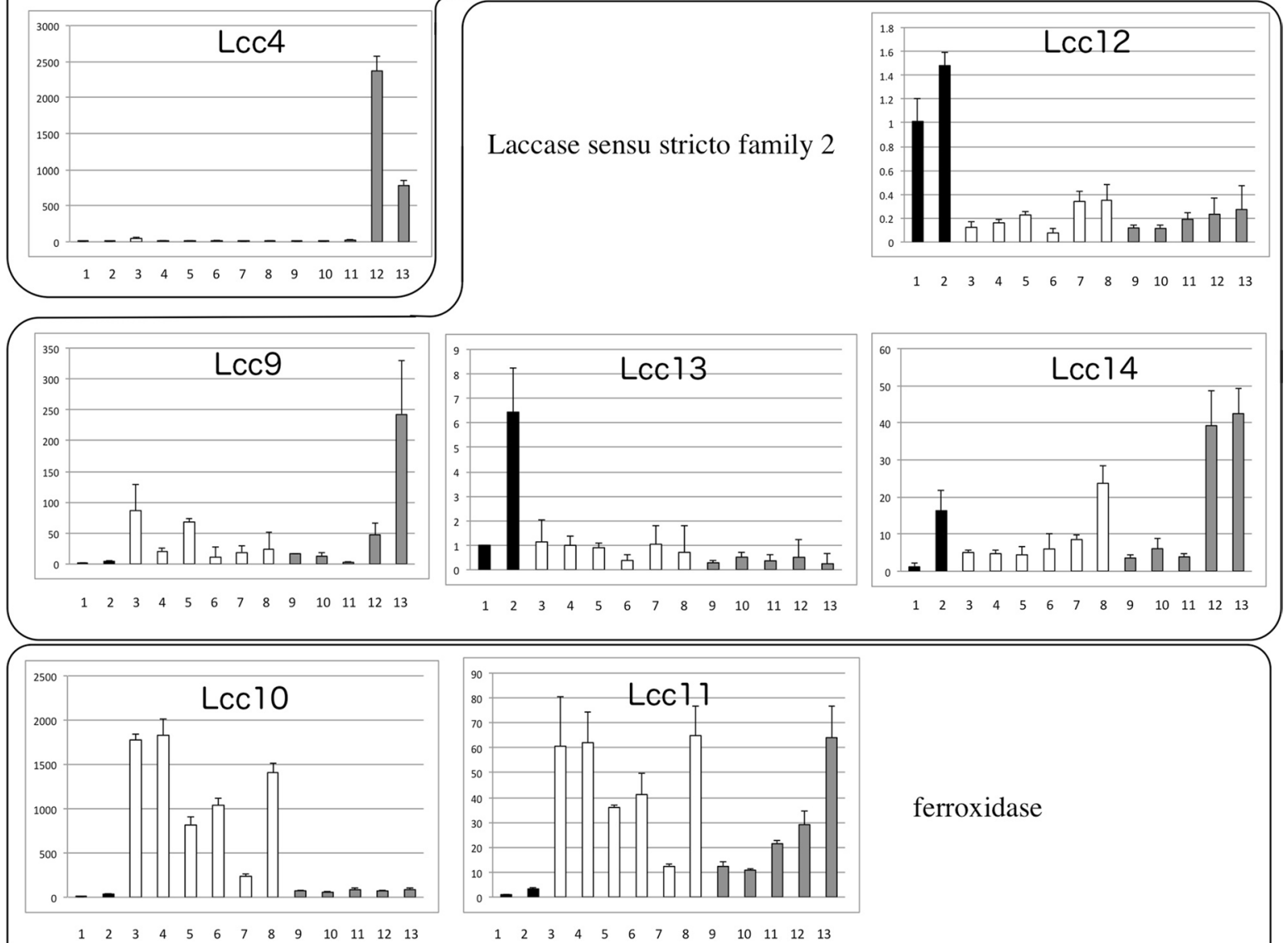

ferroxidase 
(See figure on previous page.)

Fig. 4 Transcription pattern of laccase encoding genes in L. edodes. Transcription levels of I cc1 through /cc7, Icc9 through /cc14. Y-axis means relative expression levels compared with expression levels of mycelia from liquid culture (1). All data points are mean $\pm S D(n=3) .1$ Mycelia from liquid culture. 2 Mycelia grown on sawdust medium. 3 Young fruiting bodies under $1 \mathrm{~cm}$ long. 4 Young fruiting bodies, $1-2 \mathrm{~cm}$. 5 Stipe of young fruiting bodies, 2-3 cm. 6 Pileus of young fruiting bodies, $2-3 \mathrm{~cm}$. 7 Stipe of young fruiting bodies, $3-5 \mathrm{~cm}$. 8 Pileus of young fruiting bodies, $3-5 \mathrm{~cm}$. $9 \mathrm{Gills}$ of mature fruiting body; 10 gills of fruiting body 1 day after harvest; 11 gills of fruiting body 2 days after harvest; 12 gills of fruiting body 3 days after harvest; 13 gills of fruiting body 4 days after harvest. Black Bar indicates transcription in mycelia, white bar indicates transcription in growing fruiting body and gray bar indicates transcription in gills of fruiting body after harvest

The ferroxidases, $l c c 10$ and $l c c 11$, were expressed specifically in fruiting bodies (Fig. 4). Gene lcc10 was expressed most strongly in fresh fruiting bodies, while lcc11 was expressed in fresh fruiting bodies but showed an increase in expression after harvest. The two genes were not transcribed in mycelia, suggesting that these two genes are fruiting body specific.

\section{Discussion}

Previously, 11 laccase encoding genes (lcc1 through $l c c 11$ ) were reported for L. edodes (Additional file 1: Table S6, Wong et al. 2013). In this paper, we identified three new laccase genes in L. edodes D703PP-9 (lcc12-14). Subsequent analysis showed that products of genes $l c c 10$ and lcc11 (Wong et al. 2013) are actually not laccases sensu stricto but are ferroxidases instead, bringing the total to 11 laccases sensu stricto in D703PP-9. Phylogenetic mapping of the 13 multicopper oxidases in L. edodes showed that they can be classified into laccase sensu stricto subfamily 1, sensu stricto subfamily 2, and ferroxidases (Fig. 1; Table 2). On the other hand, we could not identify lcc8 (Wong et al. 2013) in D703PP-9. This would depend on far genetic distance of D703PP-9 from Asian $L$. edodes strains (Miyazaki and Neda 2004). We also could not amplify $l c c 8$ from $\mathrm{H} 600$ cDNAs (data not shown). Therefore, further genomic comparison among several L. edodes strains is needed to reveal the exact number of multicopper oxidases in L. edodes genome.

We investigated expression patterns of multicopper oxidases in three stages of the L. edodes life cycle, mycelia, growing fruiting bodies, and fruiting bodies after harvest (Fig. 4). We found that $l c c 1, l c c 6, l c c 5$ (laccase sensu stricto subfamily 1 group A), and $l c c 12, l c c 13$, and lcc14 (laccase sensu stricto subfamily 2) were expressed in mycelia (Fig. 4), and Lcc1, Lcc6, Lcc5 and Lcc13 are found to be secreted into sawdust medium (Additional file 1: Figure S2; Table S3, Nagai et al. 2002, 2009). In contrast to multicopper oxidases expressed in mycelia, almost all multicopper oxidases are expressed in $L$. edodes fruiting bodies. Multicopper oxidases in laccase sensu stricto subfamily 1 group B $(l c c 2, l c c 3, l c c 4$ and $l c c 7$ ) and ferroxidases (lcc10 and $l c c 11)$ were expressed mainly in fruiting bodies but transcribed at low levels or not at all in mycelia (Fig. 4). These observation suggest that laccases in same group in L. edodes share expression patters. On the other hand, we earlier revealed that many genes involved in senescence of fruiting bodies of $L$. edodes are expressed after harvest (Sakamoto et al. 2009, 2012). Some multicopper oxidases transcribed after harvest must be involved in browning of fruiting bodies after harvest coordinately with tyrosinase (Nagai et al. 2003; Sakamoto et al. 2009, 2012; Sato et al. 2009). Many multicopper oxidases of all groups, $l c c 2, l c c 3, l c c 4, l c c 5, l c c 9$, $l c c 11$, and $l c c 14$, were transcribed in fruiting bodies after harvest. This observation suggests that global transcription changes for multicopper oxidase-encoding genes occur at the stage of senescence.

Some of the laccases that share sequence similarities possibly have similar biological functions. We found that L. edodes laccases in sensu stricto subfamily 1 can be divided into two major groups by sequence similarities and expression patterns, one is group of laccases secreted from mycelia (lcc1, lcc5, lcc6: group A) and the other is a group of laccases mainly expressed in fruiting body $(l c c 2, l c c 3, l c c 4$ and $l c c 7$ : group B). In laccase sensu stricto subfamily 1 group A, Lcc1 and Lcc6 are closely related (Fig. 1). Both of the two laccases are expressed in cultivated mycelia and are secreted (Fig. 4, Additional file 1: Figure S3). We compared multicopper oxidases in Marasmiaceae species [L. edodes, O. olearius (Wawrzyn et al. 2012), D. bispora: http:/genome.jgi.doe.gov/Denbi1/ Denbi1.home.html, M. perniciosa (Mondego et al. 2008) and G. luxurians (Kohler et al. 2015)], for which public genome sequences are available, and only G. luxurians has multiple laccases closely related to Lcc1 and Lcc6. On the other hand, Lcc5, which has higher similarity to Lcc1 and Lcc6, is clustered in a different clade in the phylogenetic tree (Fig. 1), but clusters with laccases in all Marasmiaceae species tested, except for the pathogenic fungus $M$. perniciosa. Lcc5 is expressed and secreted into sawdust media similarly to $l c c 6$, suggesting that Lcc5 and Lcc6 may have a similar biological function in hyphal growth in sawdust media. Laccases are presumably involved in lignin degradation by white-rot fungi (Baldrian 2006; Eggert et al. 1997; Rivera-Hoyos et al. 2013; Thurston 1994); therefore, laccase secreted from mycelia grown on sawdust medium in laccase sensu stricto subfamily 1 group A $(l c c 1, l c c 5$ and $l c c 6)$ may be 
involved in lignin degradation as well. Only the pathogenic fungus $M$. perniciosa does not have these laccases, suggesting that $M$. perniciosa, which does not rely on rotting wood for growth, might not need this type of laccase. On the other hand, Lcc1 is involved in hyphal morphogenesis and cell wall synthesis in L. edodes (Nakade et al. 2011). Furthermore, several research groups have reported that laccase activity is high in colonized mycelium and decreases during fruiting body development (Elisashvili et al. 2008; Ohga et al. 1998, 2000; Ohga and Royse 2001; Kües and Liu 2000). It has also been reported that phenoloxidase (including laccase) activity correlates with fruiting body formation in mushrooms (Leonard and Phillips 1973; Suguimoto et al. 2001; Vnenchak and Schwalb 1989). Furthermore, Magae et al. (2005) suggested that Bromophenol Blue decolorization ability correlates with fruiting body formation, and Lcc1 in $L$. edodes has this ability. More recently, overexpression of laccase in Hypsizygus marmoreus enhances fruiting body production (Zhang et al. 2015). These observations collectively suggest that Lcc1 in L. edodes may be correlated with fruiting body formation (Nakade et al. 2011). Therefore, further studies are needed to reveal the relationship between these secreted types of laccases in sensu stricto subfamily 1 group A and hyphal development or fruiting body formation.

Laccases in another group of laccase sensu stricto subfamily 1 , groupB: $l c c 2, l c c 3$, $l c c 4$ and $l c c 7$, are mainly expressed in fruiting bodies. All Marasmiaceae species tested have this type of laccase (Fig. 1). This suggests that laccases in sensu stricto subfamily 1 group B could have common biological roles in Marasmiaceae species. $l c c 2$, $l c c 3$ and $l c c 7$ are transcribed in fresh fruiting bodies, and $l c c 2, l c c 3$ and $l c c 4$ are transcribed in fruiting bodies after harvest (Fig. 4, Additional file 1: Figures S4, S5). This suggests that these laccases are performing their main role in fruiting bodies. This is supported by other findings; for example, Lcc4 can catalyze the oxidization of L-DOPA, and is involved in melanin synthesis (gill browning), but Lcc1 and Lcc6 cannot (Nagai et al. 2003, 2009) or are weak catalysts compared to Lcc4 (Nagai et al. 2003; Sakamoto et al. 2012; Wong et al. 2013). To clarify the classification and biological functions of the laccase sensu stricto subfamily 1 group B in Marasmiaceae species, further enzymatic investigations in other laccases of this subfamily are needed.

Marasmiaceae species also have two different types of laccases in sensu stricto subfamily 2 . One is a group including Lcc12 and the other is a group including Lcc9, Lcc13 and Lcc14. Interestingly, laccase sensu stricto subfamily 2 is generally conserved in limited species of the Agaricales, such as L. edodes, F. velutipes, $C$. cinerea, A. bisporus and P. ostreatus (Fig. 1). There is little information on laccase sensu stricto subfamily 2 in $L$. edodes. Furthermore, enzymatic characteristics and biological functions of laccases in this subfamily have not been well characterized. $l c c 13$ is transcribed fairly abundantly in sawdust medium (Fig. 4) and Lcc13 secreted into the medium (Additional file 1: Figure S2). Three of four laccases in sensu stricto subfamily 2 in $L$. edodes are transcribed in mycelia and have a signal peptide for secretion; therefore, laccases in sensu stricto subfamily 2 are likely to function as extracellular enzymes for lignin degradation.

Wong et al. (2013) reported that Lcc10 and Lcc11 in $L$. edodes can be classified as laccases, but our data suggests that these two laccases could be categorized as ferroxidases following the classification of multicopper oxidases according to Hoegger et al. (2006) and Kües and Rühl (2011). Lcc10 is classified as a fungal ferroxidase (Fet3type) conserved in basidiomycetes (Fig. 1, Kües and Rühl 2011). G. luxurians and O. olearius of the Marasmiaceae tested have a similar type of multicopper oxidase. Lcc11 is classified as a ferroxidase/laccase conserved in a wide range of basidiomycetes and ascomycetes, but only $G$. luxurians of the Marasmiaceae tested has a similar type of multicopper oxidase. These ferroxidases are specifically expressed in L. edodes fruiting bodies, but further studies are needed to determine their biological functions.

In conclusion, we found 13 distinct multicopper oxidases in the L. edodes D703PP-9 genome. These multicopper oxidases can be classified by sequence similarities and differentiated functionally, like chitin synthase in Yarrowia lipolytica (Sheng et al. 2013). The 1000 Fungal Genomes Project provided large amounts of genome data for basidiomycetous fungi, and wood decay mechanisms are discussed based on plant cell wall degradation related enzymes, such as lignin and cellulose degradation enzymes (Floudas et al. 2012, 2015; Riley et al. 2014). Relationship between evolution of lignin peroxidases and basidiomycetous fungi has been well discussed in the papers. More laccases are found in basidiomycetous fungal genomes compare with fungal peroxidases (Floudas et al. 2012). Therefore, biological function of laccase could be more diverse. Further enzymatic study and functional analysis will provide insights into how this multiplicity of laccases evolved and became functionally differentiated for lignin degradation, fruiting body development and fruiting body coloration.

\section{Additional file}

Additional file 1. Additional information of L. edodes multicopper oxidases, such as signal peptide prediction, enzyme purificaition, expression patterns, primer design, data set for phylogenetic analysis, and sequence infromation. 


\section{Authors' contributions}

YS carried out all protein purification, sequence analysis, and phylogenetic analysis. KN constructed libraries for next generation sequence. KY and SN contributed next generation sequence analysis and de novo assemble. KM carried out linkage mapping analysis. SS, AFP and NK carried out real-time PCR analysis. All authors have read and approved the final manuscript.

\section{Author details}

${ }^{1}$ Iwate Biotechnology Research Center, 22-174-4 Narita, Kitakami-shi, Iwate 024-0003, Japan. ${ }^{2}$ TSUMURA and Co., 3586 Yoshiwara, Ami-machi, Inashiki-gun, Ibaraki 300-1192, Japan. ${ }^{3}$ Graduate School of Agricultural Science, Kobe University, 1-1 Rokkodai, Nada-ku, Kobe 657-8501, Japan. ${ }^{4}$ Kyushu Research Center Forestry and Forest Products Research Institute, 4-11-16 Kurokami, Kumamoto, Kumamoto 860-0862, Japan. ${ }^{5}$ College of Life Sciences, Fujian Agriculture and Forestry University, Fuzhou 350002, People's Republic of China. ${ }^{6}$ Faculty of Agriculture, Utsunomiya University, 350 Mine-machi, Utsunomiya, Tochigi 321-8505, Japan.

\section{Acknowledgements}

We thank Dr. Toshitsugu Sato of the Kitami Institute of Technology and Dr. Masaru Nagai of the Institute for Environmental Sciences for giving us helpful suggestions. We further thank Mrs. Akiko Uchidate and Miss Ayumi Obara for their help with the experiments.

\section{Compliance with ethical guidelines}

\section{Competing interests}

The authors declare that they have no competing interests. This study was funded by Iwate Biotechnology Research Center and Research Center Forestry and Forest Products Research Institute.

Received: 1 September 2015 Accepted: 8 September 2015 Published online: 17 September 2015

\section{References}

Baldrian P (2006) Fungal laccases-occurrence and properties. FEMS Microbiol Rev 30:215-242

Castanera R, Pérez G, Omarini A, Alfaro M, Pisabarro AG, Faraco V, Amore A, Ramírez L (2012) Transcriptional and enzymatic profiling of Pleurotus ostreatus laccase genes in submerged and solid-state fermentation cultures. Appl Environ Microbiol 78:4037-4045

Courty PE, Hoegger PJ, Kilaru S, Kohler A, Buée M, Garbaye J, Martin F, Kües $U$ (2009) Phylogenetic analysis, genomic organization, and expression analysis of multi-copper oxidases in the ectomycorrhizal basidiomycete Laccaria bicolor. New Phytol 182:736-750

Eggert C, Temp U, Eriksson K-EL (1997) Laccase is essential for lignin degradation by the white-rot fungus Pycnoporus cinnabarinus. FEBS Lett 407:89-92

Elisashvili V, Kachlishvili E, Penninckx MJ (2008) Lignocellulolytic enzymes profile during growth and fruiting of Pleurotus ostreatus on wheat straw and tree leaves. Acta Microbiol Immunol Hung 55:157-168

Ferraroni M, Myasoedova NM, Schmatchenko V, Leontievsky AA, Golovleva LA, Scozzafava A, Briganti F (2007) Crystal structure of a blue laccase from Lentinus tigrinus: evidences for intermediates in the molecular oxygen reductive splitting by multicopper oxidases. BMC Struct Biol 7:60

Floudas D, Binder M, Riley R, Barry K, Blanchette RA, Henrissat B, Martínez AT, Otillar R, Spatafora JW, Yadav JS, Aerts A, Benoit I, Boyd A, Carlson A, Copeland A, Coutinho PM, de Vries RP, Ferreira P, Findley K, Foster B, Gaskell J, Glotzer D, Górecki P, Heitman J, Hesse C, Hori C, Igarashi K, Jurgens JA, Kallen N, Kersten P, Kohler A, Kües U, Kumar TKA, Kuo A, LaButti K, Larrondo LF, Lindquist E, Ling A, Lombard V, Lucas S, Lundell T, Martin R, McLaughlin DJ, Morgenstern I, Morin E, Murat C, Nagy LG, Nolan M, Ohm RA, Patyshakuliyeva A, Rokas A, Ruiz-Dueñas FJ, Sabat G, Salamov A, Samejima M, Schmutz J, Slot JC, St John F, Stenlid J, Sun H, Sun S, Syed K, Tsang A, Wiebenga A, Young D, Pisabarro A, Eastwood DC, Martin F, Cullen D, Grigoriev IV, Hibbett DS (2012) The Paleozoic origin of enzymatic lignin decomposition reconstructed from 31 fungal genomes. Science 336:1715-1719
Floudas D, Held BW, Riley R, Nagy LG, Koehler G, Ransdell AS, Younus H, Chow J, Chiniquy J, Lipzen A, Tritt A, Sun H, Haridas S, LaButti K, Ohm RA, Kües U, Blanchette RA, Grigoriev IV, Minto RE, Hibbett DS (2015) Evolution of novel wood decay mechanisms in Agaricales revealed by the genome sequences of Fistulina hepatica and Cylindrobasidium torrendii. Fung Genet Biol 76:78-92

Fujihiro S, Higuchi R, Hisamatsu S, Sonoki S (2009) Metabolism of hydroxylated PCB congeners by cloned laccase isoforms. Appl Microbiol Biotechnol 82:853-860

Galhaup C, Goller S, Peterbauer CK, Strauss J, Haltrich D (2002) Characterization of the major laccase isoenzyme from Trametes pubescens and regulation of its synthesis by metal ions. Microbiol 148:2159-2169

Hirano T, Sato T, Okawa K, Kanda K, Yaegashi K, Enei H (1999) Isolation and characterization of the glyceraldehyde-3-phosphate dehydrogenase gene of Lentinus edodes. Biosci Biotechnol Biochem 63:1223-1227

Hoegger PJ, Kilaru S, James TY, Thacker JR, Kües U (2006) Phylogenetic comparison and classification of laccase and related multicopper oxidase protein sequences. FEBS J 273:2308-2326

Hoopes JT, Dean JF (2004) Ferroxidase activity in a laccase-like multicopper oxidase from Liriodendron tulipifera. Plant Physiol Biochem 42:27-33

Jeon J-R, Murugesan K, Kim Y-M, Kim E-J, Chang Y-S (2008) Synergistic effect of laccase mediators on pentachlorophenol removal by Ganoderma lucidum laccase. Appl Microbiol Biotechnol 81:783-790

Jönsson LJ, Saloheimo M, Penttilä M (1997) Laccase from the white-rot fungus Trametes versicolor: CDNA cloning of Icc1 and expression in Pichia pastoris. Curr Genet 32:425-430

Kilaru S, Hoegger PJ, Kües U (2006) The laccase multi-gene family in Coprinopsis cinerea has seventeen different members that divide into two distinct subfamilies. Curr Genet 50:45-60

Kohler A, Kuo A, Nagy LG, Morin E, Barry KW, Buscot F, Canbäck B, Choi C, Cichocki N, Clum A, Colpaert J, Copeland A, Costa MD, Doré J, Floudas D, Gay G, Girlanda M, Henrissat B, Herrmann S, Hess J, Högberg N, Johansson T, Khouja H-R, LaButti K, Lahrmann U, Levasseur A, Lindquist EA, Lipzen A, Marmeisse R, Martino E, Murat C, Ngan CY, Nehls U, Plett JM, Pringle A, Ohm RA, Perotto S, Peter M, Riley R, Rineau F, Ruytinx J, Salamov A, Shah F, Sun H, Tarkka M, Tritt A, Veneault-Fourrey C, Zuccaro A, Tunlid A, Grigoriev IV, Hibbett DS, Martin F (2015) Convergent losses of decay mechanisms and rapid turnover of symbiosis genes in mycorrhizal mutualists. Nat Genet 47:410-415

Kosambi DD (1943) The estimation of map distances from recombination values. Ann Eugen 12:172-175

Kües U, Liu Y (2000) Fruiting body production in basidiomycetes. Appl Microbiol Biotech 54:141-152

Kües U, Rühl M (2011) Multiple multi-copper oxidase gene families in basidiomycetes-what for? Curr Genom 12:72-94

Kumar SVS, Phale PS, Durani S, Wangikar PP (2003) Combined sequence and structure analysis of the fungal laccase family. Biotechnol Bioeng 83:386-394

Lander ES, Green P, Abrahamson J, Barlow A, Daly MJ, Lincoln SE, Newberg LA, Newburg L (1987) MAPMAKER: an interactive computer package for constructing primary genetic linkage maps of experimental and natural populations. Genomics 1:174-181

Leonard TJ, Phillips LE (1973) Study of phenoloxidase activity during the reproductive cycle in Schizophyllum commune. J Bacteriol 114:7-10

Leonowicz A, Cho NS, Luterek J, Wilkolazka A, Wojtas-Wasilewska M, Matuszewska A, Hofrichter M, Wesenberg D, Rogalski J (2001) Fungal laccase: properties and activity on lignin. J Basic Microbiol 41:185-227

Lettera V, Piscitelli A, Leo G, Birolo L, Pezzella C, Sannia G (2010) Identification of a new member of Pleurotus ostreatus laccase family from mature fruiting body. Fung Biol 114:724-730

Livak KJ, Schmittgen TD (2001) Analysis of relative gene expression data using real-time quantitative PCR and the 2(-Delta Delta $C(T)$ ) method. Methods 25:402-408

Madhavan S, Krause K, Jung E-M, Kothe E (2014) Differential regulation of multi-copper oxidases in Schizophyllum commune during sexual development. Mycol Prog 13:1199-1206

Magae Y, Akahane K, Nakamura K, Tsunoda S (2005) Simple colorimetric method for detecting degenerate strains of the cultivated basidiomycete Flammulina velutipes (Enokitake). Appl Environ Microbiol 71:6388-6389

Martin F, Aerts A, Ahrén D, Brun A, Danchin EGJ, Duchaussoy F, Gibon J, Kohler A, Lindquist E, Pereda V, Salamov A, Shapiro HJ, Wuyts J, Blaudez D, Buée M, Brokstein P, Canbäck B, Cohen D, Courty PE, Coutinho PM, Delaruelle C, Detter JC, Deveau A, DiFazio S, Duplessis S, Fraissinet-Tachet L, Lucic 
E, Frey-Klett P, Fourrey C, Feussner I, Gay G, Grimwood J, Hoegger PJ, Jain P, Kilaru S, Labbé J, Lin YC, Legué V, Le Tacon F, Marmeisse R, Melayah D, Montanini B, Muratet M, Nehls U, Niculita-Hirzel H, Oudot-Le Secq MP, Peter M, Quesneville H, Rajashekar B, Reich M, Rouhier N, Schmutz J, Yin T, Chalot M, Henrissat B, Kües U, Lucas S, Van de Peer Y, Podila GK, Polle A, Pukkila PJ, Richardson PM, Rouzé P, Sanders IR, Stajich JE, Tunlid A, Tuskan G, Grigoriev IV (2008) The genome of Laccaria bicolor provides insights into mycorrhizal symbiosis. Nature 452:88-92

Miyazaki K, Neda H (2004) Evaluation of the use of outbred lines for screening of genetic markers in Shiitake (Lentinula edodes). Breed Sci 54:75-78

Miyazaki K, Huang F, Zhang B, Shiraishi S, Sakai M, Shimaya C, Shishido K (2008) Genetic map of a basidiomycete fungus, Lentinula edodes (shiitake mushroom), constructed by tetrad analysis. Breed Sci 58:23-30

Mondego JMC, Carazzolle MF, Costa GGL, Formighieri EF, Parizzi LP, Rincones J, Cotomacci C, Carraro DM, Cunha AF, Carrer H, Vidal RO, Estrela RC, García O, Thomazella DPT, de Oliveira BV, Pires AB, Rio MCS, Araújo MRR, de Moraes MH, Castro LAB, Gramacho KP, Gonçalves MS, Neto JPM, Neto AG, Barbosa LV, Guiltinan MJ, Bailey BA, Meinhardt LW, Cascardo JC, Pereira GAG (2008) A genome survey of Moniliophthora perniciosa gives new insights into Witches'Broom Disease of cacao. BMC Genom 9:548. doi:10.1186/1471-2164-9-548

Morin E, Kohler A, Baker AR, Foulongne-Oriol M, Lombard V, Nagy LG, Ohm RA, Patyshakuliyeva A, Brun A, Aerts AL, Bailey AM, Billette C, Coutinho PM, Deakin G, Doddapaneni H, Floudas D, Grimwood J, Hildén K, Kües U, Labutti KM, Lapidus A, Lindquist EA, Lucas SM, Murat C, Riley RW, Salamov AA, Schmutz J, Subramanian V, Wösten HAB, Xu J, Eastwood DC, Foster GD, Sonnenberg ASM, Cullen D, de Vries RP, Lundell T, Hibbett DS, Henrissat B, Burton KS, Kerrigan RW, Challen MP, Grigoriev IV, Martin F (2012) Genome sequence of the button mushroom Agaricus bisporus reveals mechanisms governing adaptation to a humic-rich ecological niche. Proc Natl Acad Sci 109:17501-17506

Nagai M, Sato T, Watanabe H, Saito K, Kawata M, Enei H (2002) Purification and characterization of an extracellular laccase from the edible mushroom Lentinula edodes, and decolorization of chemically different dyes. Appl Microbiol Biotechol 60:327-335

Nagai M, Kawata M, Watanabe H, Ogawa M, Saito K, Takesawa T, Kanda K, Sato $T$ (2003) Important role of fungal intracellular laccase for melanin synthesis: purification and characterization of an intracellular laccase from Lentinula edodes fruit bodies. Microbiol 149:2455-2462

Nagai M, Sakamoto Y, Nakade K, Sato T (2009) Purification of a novel extracellular laccase from solid-state culture of the edible mushroom Lentinula edodes. Mycosci 50:308-312

Nakade K, Watanabe H, Sakamoto Y, Sato T (2011) Gene silencing of the Lentinula edodes Icc1 gene by expression of a homologous inverted repeat sequence. Microbiol Res 166:484-493

Nosanchuk JD, Casadevall A (2003) The contribution of melanin to microbial pathogenesis. Cell Microbiol 5:203-223

Ohga S, Royse DJ (2001) Transcriptional regulation of laccase and cellulase genes during growth and fruiting of Lentinula edodes on supplemented sawdust. FEMS Microbiol Lett 201:111-115

Ohga S, Wood DA, Smith M, Thurston CF (1998) Transcriptional regulation of laccase and cellulase genes of Agaricus bisporus during fruit body development on solid substrate. Mush Sci Biotechnol 6:107-113

Ohga S, Cho N, Thurston C, Wood D (2000) Transcriptional regulation of laccase and cellulase in relation to fruit body formation in the mycelium of Lentinula edodes on a sawdust-based substrate. Mycosci 41:149-153

Ohm RA, de Jong JF, Lugones LG, Aerts A, Kothe E, Stajich JE, de Vries RP, Record E, Levasseur A, Baker SE, Bartholomew KA, Coutinho PM, Erdmann S, Fowler TJ, Gathman AC, Lombard V, Henrissat B, Knabe N, Kües U, Lilly WW, Lindquist E, Lucas S, Magnuson JK, Piumi F, Raudaskoski M, Salamov A, Schmutz J, Schwarze FWMR, VanKuyk PA, Horton JS, Grigoriev IV, Wösten HAB (2010) Genome sequence of the model mushroom Schizophyllum commune. Nat Biotechnol 28:957-963

Palmieri G, Giardina P, Bianco C, Fontanella B, Sannia G (2000) Copper induction of laccase isoenzymes in the ligninolytic fungus Pleurotus ostreatus. Appl Environ Microbiol 66:920-924

Pezzella C, Lettera V, Piscitelli A, Giardina P, Sannia G (2013) Transcriptional analysis of Pleurotus ostreatus laccase genes. Appl Microbiol Biotech 97:705-717
Piontek K, Antorini M, Choinowski T (2002) Crystal structure of a laccase from the fungus Trametes versicolor at 1.90-A resolution containing a full complement of coppers. J Biol Chem 277:37663-37669

Ranocha P, Chabannes M, Chamayou S, Danoun S, Jauneau A, Boudet A-M, Goffner D (2002) Laccase down-regulation causes alterations in phenolic metabolism and cell wall structure in poplar. Plant Physiol 129:145-155

Riley R, Salamov AA, Brown DW, Nagy LG, Floudas D, Held BW, Levasseur A, Lombard V, Morin E, Otillar R, Lindquist EA, Sun H, LaButti KM, Schmutz J, Jabbour D, Luo H, Baker SE, Pisabarro AG, Walton JD, Blanchette RA, Henrissat B, Martin F, Cullen D, Hibbett DS, Grigoriev IV (2014) Extensive sampling of basidiomycete genomes demonstrates inadequacy of the white-rot/brown-rot paradigm for wood decay fungi. Proc Nat Acad Sci 111:9923-9928

Rivera-Hoyos CM, Morales-Álvarez ED, Poutou-Piñales RA, Pedroza-Rodríguez AM, Rodríguez-Vázquez R, Delgado-Boada JM (2013) Fungal laccases. Fung Biol Rev 27:67-82

Sakamoto Y, Irie T, Sato T (2005) Isolation and characterization of a fruiting body-specific exo- $\beta$-1,3-glucanase-encoding gene, exg1, from Lentinula edodes. Curr Genet 47:244-252

Sakamoto Y, Nakade K, Yano A, Nakagawa Y, Hirano T, Irie T, Watanabe H, Nagai M, Sato T (2008) Heterologous expression of Icc1 from Lentinula edodes in tobacco BY-2 cells results in the production an active, secreted form of fungal laccase. Appl Microbiol Biotechnol 79:971-980

Sakamoto Y, Nakade K, Sato T (2009) Characterization of the post-harvest changes in gene transcription in the gill of the Lentinula edodes fruiting body. Curr Genet 55:409-423

Sakamoto Y, Nakade K, Konno N, Sato T (2012) Senescence of the Lentinula edodes fruiting body after harvesting. In: Kapiris K (ed) Food quality. InTech, Rijeka, Croatia, pp 83-110. doi:10.5772/1871

Sato T, Kanda K, Okawa K, Takahashi M, Watanabe H, Hirano T, Yaegashi K, Sakamoto Y, Uchimiya H (2009) The tyrosinase-encoding gene of Lentinula edodes, Letyr, is abundantly expressed in the gills of the fruit-body during post-harvest preservation. Biosci Biotechnol Biochem 73:1042-1047

Sheng W, Yamashita S, Ohta A, Horiuchi H (2013) Functional differentiation of chitin synthases in Yarrowia lipolytica. Biosci Biotechnol Biochem 77:1275-1281

Stajich JE, Wilke SK, Ahrén D, Au CH, Birren BW, Borodovsky M, Burns C, Canbäck B, Casselton LA, Cheng CK, Deng J, Dietrich FS, Fargo DC, Farman ML, Gathman AC, Goldberg J, Guigó R, Hoegger PJ, Hooker JB, Huggins A, James TY, Kamada T, Kilaru S, Kodira C, Kües U, Kupfer D, Kwan HS, Lomsadze A, Li W, Lilly WW, Ma L-J, Mackey AJ, Manning G, Martin F, Muraguchi H, Natvig DO, Palmerini H, Ramesh MA, Rehmeyer CJ, Roe BA, Shenoy N, Stanke M, Ter-Hovhannisyan V, Tunlid A, Velagapudi R, Vision TJ, Zeng Q, Zolan ME, Pukkila PJ (2010) Insights into evolution of multicellular fungi from the assembled chromosomes of the mushroom Coprinopsis cinerea (Coprinus cinereus). Proc Nat Acad Sci 107:11889-11894

Sterjiades R, Dean JF, Eriksson KE (1992) Laccase from sycamore maple (Acer pseudoplatanus) polymerizes monolignols. Plant Physiol 99:1162-1168

Suguimoto HH, Barbosa AM, Dekker RF, Castro-Gomez RJ (2001) Veratryl alcohol stimulates fruiting body formation in the oyster mushroom, Pleurotus ostreatus. FEMS Microbiol Lett 194:235-238

Thurston C (1994) The structure and function of fungal laccases. Microbiol 140:19-26

Ullah MA, Bedford CT, Evans CS (2000) Reactions of pentachlorophenol with laccase from Coriolus versicolor. Appl Microbiol Biotechnol 53:230-234

Vnenchak P, Schwalb MN (1989) Phenol oxidase activity during development of Coprinus cinereus. Mycol Res 93:546-548

Wang W, Liu F, Jiang Y, Wu G, Guo L, Chen R, Chen B, Lu Y, Dai Y, Xie B (2015) The multigene family of fungal laccases and their expression in the white rot basidiomycete Flammulina velutipes. Gene 563:142-149

Wawrzyn GT, Quin MB, Choudhary S, López-Gallego F, Schmidt-Dannert C (2012) Draft genome of Omphalotus olearius provides a predictive framework for sesquiterpenoid natural product biosynthesis in Basidiomycota. Chem Biol 19:772-783

Wong K-S, Cheung M-K, Au C-H, Kwan H-S (2013) A novel Lentinula edodes laccase and its comparative enzymology suggest guaiacol-based laccase engineering for bioremediation. PLoS One 8:e66426 
Yano A, Kikuchi S, Nakagawa Y, Sakamoto Y, Sato T (2009) Secretory expression of the non-secretory-type Lentinula edodes laccase by Aspergillus oryzae. Microbiol Res 164:642-649

Zhang J, Chen H, Chen M, Ren A, Huang J, Wang H, Zhao M, Feng Z (2015)

Cloning and functional analysis of a laccase gene during fruiting body formation in Hypsizygus marmoreus. Microbiol Res 179:54-63
Zhao J, Kwan HS (1999) Characterization, molecular cloning, and differential expression analysis of laccase genes from the edible mushroom Lentinula edodes. Appl Environ Microbiol 65:4908-4913

\section{Submit your manuscript to a SpringerOpen ${ }^{\odot}$} journal and benefit from:

- Convenient online submission

- Rigorous peer review

- Immediate publication on acceptance

- Open access: articles freely available online

- High visibility within the field

- Retaining the copyright to your article

Submit your next manuscript at $\boldsymbol{~ s p r i n g e r o p e n . c o m ~}$ 